\title{
PROJETO MORADA SÃO PEDRO: DA INSTITUCIONALIZAÇÃO À DESINSTITUCIONALIZAÇÃO EM SAÚDE MENTAL ${ }^{1}$ “MORADA SÃO PEDRO” PROJECT: FROM INSTITUTIONALIZATION TO DEINSTITUTIONALIZATION IN MENTAL HEALTH PROYECTO MORADA DE SÃO PEDRO: DE LA INSTITUCIONALIZACIÓN A LA DESINSTITUCIONALIZACIÓN EN LA SALUD MENTAL
}

\author{
Marya Gorete Belini ${ }^{2}$, Alice Hirdes ${ }^{3}$
}

${ }^{1}$ Monografia apresentada como requisito à obtenção do título de Enfermeiro.

${ }^{2}$ Enfermeira da Área Indígena de Cacique Doble, RS. Formada pela Universidade Regional Integrada do Alto Uruguai e das Missões (URI).

${ }^{3}$ Enfermeira. Docente do Centro Universitário Feevale, em Novo Hambrugo, RS. Mestre em Enfermagem pela Universidade Federal de Santa Catarina (UFSC). Orientadora do estudo.

PALAVRAS-CHAVE: Desinstitucionalização. Apoio social. Saúde mental.

KEYWORDS: Deinstitutionalization. Social support. Mental health.

PALABRAS CLAVE: Desinstitucionalización. Apoyo social. Salud mental.
RESUMO: Este estudo tem como objetivo investigar junto aos profissionais vinculados ao Projeto Morada São Pedro o processo de desinstitucionalização da loucura, com vistas à construção de um referencial teórico/prático sobre residências terapêuticas. Trata-se de uma pesquisa qualitativa, realizada através de questionário semi-estruturado, com seis profissionais de saúde mental. Os resultados apontam para a reforma psiquiátrica como uma forma de incluir as pessoas na sociedade, de respeitar os direitos individuais, com um cuidado sensível, a necessidade de investir nas potencialidades e possibilidades de o indivíduo exercer sua subjetividade e singularidade, possibilitando uma nova visibilidade, no sentido de os usuários estarem se assumindo como cidadãos na sociedade. Conclui-se que é preciso construir um referencial teórico embasado nas práticas que se efetivam nas residências terapêuticas, permitindo reflexões, construindo conceitos para os trabalhadores de saúde mental consolidarem avanços nos novos dispositivos em saúde mental no contexto da reforma psiquiátrica.

ABSTRACT: This study aims at investigating the process of deinstitutionalization of madness, as seen by professionals involved in a project called "Morada São Pedro", as well as at constructing a theoretical/practical reference on therapeutic homes. It is a qualitative research in which semi-structured questionnaires were filled out by six professionals in mental health. Results point out psychiatric reform as a way to include people in society and respect individual rights. This should be done with sensitive care, the need to invest in the person's potential and possibilities concerning his/her subjectivity and uniqueness. This fact may lead to new visibility, in the sense that the people may become actual citizens. I conclude that it is necessary to construct some theoretical reference based on practices that take place in therapeutic homes. Thus, workers in mental health would reflect and construct concepts to consolidate advances in mental health in the context of psychiatric reform.

RESUMEN: Este estudio tiene como objetivo investigar junto a los profesionales vinculados al Proyecto Morada de São Pedro el proceso de desinstitucionalización de la locura, con miras a la construcción de un referencial teórico-práctico sobre las residencias terapéuticas. Se trata de una investigacion cualitativa, realizada a través de cuestionario semiestructurado, con seis profesionales de la salud mental. Los resultados apuntan para una reforma psiquiátrica como una forma de incluir a las personas en la sociedad, de respetar los derechos individuales, con un cuidado sensible; la necesidad de invertir en las potencialidades y las posibilidades del individuo ejercer su subjetividad y singularidad, posibilitando una nueva visibilidad, en el sentido de que los usuarios se asuman como ciudadanos en la sociedad. Se concluye que es necesario construir un referencial teórico basado en las prácticas realizadas en las residencias terapéuticas, permitiendo reflexiones, construyendo conceptos para que los trabajadores de la salud mental consolides avances en los nuevos dispositivos en la salud mental en el contexto da reforma psiquiátrica.
Endereço: Marya Gorete Belini

R. Edimo Luiz Tonial, 170

99.860-000 - Bairro, Cacique Doble RS

E-mail: marya_gb@yahoo.com.br
Artigo original: Pesquisa

Recebido em: 18 de maio de 2006. Aprovação final: 19 de outubro de 2006. 


\section{INTRODUÇÃO}

Na década de 70 , a luta pela democratização do país cria as condições históricas à crítica ao modelo hospitalocêntrico e manicomial existente, surgindo assim movimentos que começaram a propor novas formas de atenção em saúde mental, com o lema "Por uma Sociedade sem Manicômios". No Rio Grande do Sul, o movimento não foi diferente, e durante a década de oitenta cresceram as manifestações de trabalhadores, usuários e familiares na busca da mudança de atenção no setor. A capacitação foi um dos eixos principais da Coordenação de Saúde Mental Estadual então vigente, o que veio influenciar consideravelmente na criação de serviços substitutivos por todo o Estado, construindo novos referenciais para a rede de saúde mental. ${ }^{1}$

As mudanças no único hospital psiquiátrico público do Estado do RS que, durante décadas, centralizou o atendimento em saúde mental, foram consideradas estratégicas para a deflagração deste processo. Assim, em 1993, a Comissão de Saúde Mental do Conselho Estadual da Saúde, com diversas entidades representadas, fez aprovar o São Pedro Cidadão, assumido como projeto prioritário de governo em 1999, visando a desconstrução do Hospital Psiquiátrico São Pedro. ${ }^{1}$

Neste contexto, as residências terapêuticas constituem um dispositivo essencial à desinstitucionalização. O Ministério da Saúde define que os serviços de residências terapêuticas estão constituídos como alternativas de moradias para aquelas pessoas com internação psiquiátrica de longa permanência, que não contaram com um suporte familiar e social adequado. ${ }^{2}$ Além disso, é preciso ter sempre em mente que a questão central dos serviços de residências terapêuticas é a moradia, o morar, o viver na cidade. Assim, tais residências não são precisamente serviços de saúde, mas espaços de morar, de viver, articulados à rede de atenção psicossocial, permitindo assim um bom suporte na reabilitação psicossocial.

Atualmente, existem 256 serviços de residências terapêuticas em quatorze estados e 45 municípios do país, onde moram 1.400 pessoas. Estimativas recentes da Coordenação Nacional de Saúde Mental do Ministério da Saúde apontam para a existência de aproximadamente 12.000 pacientes internados, que poderiam ser beneficiados com os serviços de residências terapêuticas. Tais dados evidenciam a necessidade de significativa expansão do número de residências, de modo a reduzir a segregação e aumentar a reinserção social dos pacientes. ${ }^{2}$

Os pacientes psiquiátricos "estão" nos hospitais psiquiátricos e a sua reabilitação tem a ver com esse "estar". ${ }^{3} \mathrm{Um}$ dos elementos fundamentais de qualidade de vida do ser humano é representado pelo quanto o próprio "estar" se torna um "habitar" este lugar. Estar em algum lugar não significa habitar este lugar, pois estar, para o indivíduo pode ter um caráter simbólico, que pode significar não somente ter um lugar para morar, mas estar inserido na sociedade e na vida cotidiana. ${ }^{3}$ Este estar e habitar um lugar expressa-se em várias línguas: em português, casa e lar, em inglês, house e home e em espanhol, casa e hojar.

Desta forma, esta pesquisa advém da necessidade de estudar as novas práticas assistenciais não excludentes em saúde mental, e por entender que esses novos dispositivos transcendem a prática tradicional e promovem uma valorização do sujeito e uma reconstrução da identidade, aumentando sua autonomia e possibilitando a sua reinserção social.

\section{OBJETIVO}

Investigar junto aos profissionais vinculados ao Projeto Morada São Pedro o processo de desinstitucionalização da loucura, com vistas à construção de um referencial teórico/prático sobre residências terapêuticas.

\section{METODOLOGIA}

Este trabalho foi realizado no Hospital Psiquiátrico São Pedro (HPSP), na Vila São Pedro, em Porto Alegre, denominado Projeto Morada São Pedro, que busca em seu aparato a integralidade das ações, visando não somente a assistência à saúde, mas trabalhando de forma articulada, envolvendo as áreas da habitação, educação e trabalho. O projeto contempla duas áreas do Hospital, conhecidas como Vila São Pedro e Vila Salvador França. Os moradores têm suas casas construídas com a implantação de toda a infra-estrutura necessária de calçamento, água potável, luz, esgoto cloacal e pluvial.

Trata-se de uma pesquisa descritivo-analítica com abordagem qualitativa. Foram realizadas 6 entrevistas semi-estruturadas com profissionais de nível superior, dentre eles, psiquiatras, psicólogos e profissional de educação física, que obedeceram aos seguintes critérios: ser profissional de nível superior e estar vinculado ao Projeto Morada São Pedro; in- 
tegrar diferentes áreas do conhecimento e participar do projeto há pelo menos um ano. Para a análise dos dados foi seguido o caminho metodológico: ordenação, classificação e análise final dos dados. ${ }^{4}$

Os profissionais encontram-se identificados como A1, A2, A3... assegurando assim o anonimato de cada sujeito entrevistado. O projeto foi submetido à avaliação do Comitê de Ética em Pesquisa da Universidade, tendo sido aprovado (Resolução $\left.\mathrm{n}^{\mathrm{o}} .006-1 / \mathrm{TCH} / 05\right)$. Também foi encaminhado para o Comitê de Ética Independente da Divisão de Ensino e Pesquisa do Hospital Psiquiátrico São Pedro, tendo sido aprovado sem restrições. Foram respeitados os aspectos éticos referentes à pesquisa com seres humanos, conforme determina a Resolução No 196/96.

\section{ANÁLISE E DISCUSSÃO DOS DADOS}

$\mathrm{Na}$ análise dos dados, depois de extraídas as estruturas de relevância das falas dos atores sociais, foram identificadas e agrupadas nas seguintes áreas temáticas: limitações como consequência da institucionalização; resgate da cidadania como emancipação; processo educativo como cuidado: resgate de habilidades e autonomia; operacionalização das moradias.

\section{Limitações como conseqüência da institucio- nalização}

Desta área temática emerge a idéia do portador de transtorno mental como sujeito com limitações físicas e psíquicas que demandam suporte para enfrentar as exigências da vida cotidiana e melhorar sua qualidade de vida. Isso denota uma realidade encontrada nas muitas pessoas institucionalizadas há longas décadas que ainda moram nos hospitais psiquiátricos.

Para alguns autores é difícil para portadores de doenças mentais crônicas enfrentarem situações adversas no cotidiano, pois os mesmos necessitam de um grande esforço para superar as limitações impostas por sua doença e por sua condição de doente. ${ }^{6}$ Entretanto, este processo de transformação dos serviços em residências terapêuticas caracteriza-se por criar possibilidades de irem além, de transcenderem, de assumirem sozinhos seu tratamento em decorrência das perdas que vinham sofrendo com a negação do seu problema.

Alguns pontos relevantes que emergiram nas falas foram as limitações que comprometem muitas vezes o desenvolvimento das atividades rotineiras.
Percebe-se que essas situações de dificuldades foram incorporadas e intensificadas pelas pessoas com transtorno psíquico por permanecerem em um lugar extremamente fechado. De alguma forma, tiveram suas vidas roubadas pela doença mental, pois não exerciam liberdade nenhuma de escolha, não tinham possibilidade de cuidar de si mesmos e nem de exercer dignamente sua cidadania. O teu limite de frustração tem que ser bastante grande porque as coisas não acontecem na medida que nós queremos, mas acontecem na medida que eles são capazes de fazer [...] (A1).

O manicômio é o "lugar zero da troca". A tutela, a internação, têm a finalidade de subtrair as trocas e manter apenas relações de dependência social. Entretanto, a luta pela reforma na psiquiatria serviu para lutar contra aquelas relações e exclusões sociais que, agora, reinseridas fora da tutela nas trocas sociais, estarão com possibilidades materiais de participar do contrato social. Assim, as tutelas se perpetuam na forma atualizada da dependência material e social dos circuitos que concedem garantias assistenciais, e o paciente se transforma em usuário que paga o seu débito por pertencer à sociedade de troca com a dependência de instituições que estruturam uma topografia desta nova sociedade. [...] então assim de um lugar extremamente fechado onde eles recebem tudo pronto, mas por outro lado não tinham praticamente liberdade nenbuma de escolba, nem sequer de um prato de alimentação ou a hora que poderiam até tomar um banho [...] (A3).

O manicômio constituiu um paradigma dos processos de desabilitação, conquanto neste, o paciente experimente todos os elementos da vida cotidiana (do comer ao dormir, do vestir ao usufruir dos espaços, do trocar afetos ao receber ordens e a se submeter a normas), elementos que assumiram o seu grau zero, no sentido de empobrecimento humano e material. Subir a espiral significa modificar histórias subjetivas, subjetivar espaços, transformando-os em lugares de experiências, inventar, exigir, produzir recursos, reformular direitos e desmascarar privilégios. ${ }^{3}$

Uma das concepções que permitiram uma radical reordenação da forma de lidar com o portador de doença mental foi o reconhecimento deste, enquanto sujeito, que possui sua história de vida $\mathrm{e}$ desejos. ${ }^{8}$ Esta noção desloca o louco da condição de doente mental e dá ênfase ao sujeito, trazendo diversos aspectos da problemática do seu cotidiano para além das questões de saúde. É determinante a perspectiva de construção de um olhar multifacetado sobre o sujeito em sofrimento. Este olhar é consolidado a partir de uma linha de montagem entre 
as especialidades, na tentativa de construir algo de ordem no coletivo. [...] é um processo de estar se assumindo enquanto indivíduo, possibilitando novas subjetivacooes, não uma subjetivação da instituição formatada, de tu estares num espaço que tu não é o responsável que tu és a pessoa que tem que obedecer o tempo inteiro, que sempre tem uma pessoa que responda por ti, que vai dizer a hora, sempre a hora que tu tens a janta, que tens que tomar banho, a hora que tu tens que tomar o teu remédio e não possibilita que tu tenhas muitas vivências (A4).

Entretanto, o entrevistado reconhece que uma pessoa com uma longa internação psiquiátrica, na qual foram abolidos o desejo, a subjetivação, a negação aos aspectos mais elementares do seu cotidiano e, sobretudo, a liberdade, quando esta reencontra estes elementos, muitas vezes não consegue desfrutar $\mathrm{da}$ autonomia que lhe é restituída.

O trabalho de reabilitação dos pacientes nos hospitais psiquiátricos tem muito a ver com a humanização e os direitos, com a desinstitucionalização, com a subjetivação dos indivíduos, tem a ver com cada momento, com espaços concretos nos quais as pessoas podem falar, dormir, caminhar e comer; tudo isso é a vida cotidiana de cada pessoa. Essa cotidianeidade não tem legitimidade no hospital psiquiátrico, onde essas funções são reguladas, controladas, sem qualquer esquema racional global, negando as banalidades do viver e negando os lugares e o tempo. ${ }^{3}$

A subjetividade sob um ângulo de produção que não implica nos princípios da realidade, pois os mesmos instigam a ampliar a definição da subjetividade, de modo a exceder os limites da oposição clássica entre o sujeito individual e a sociedade e por esta via rever os modelos do inconsciente que estão em curso atualmente. ${ }^{9}$ Em alguns contextos sociais e semiológicos, a subjetividade individualiza-se, é responsável por si própria, posiciona-se no centro das relações de alteridade rígidas, instituídas pelas famílias, hábitos e costumes locais, leis jurídicas e, em outras condições, a subjetividade se faz coletiva, o que não significa que ela se torne restritamente social. Admite-se que cada pessoa, cada grupo social, propaga seu próprio conjunto de modelização da subjetividade inconsciente, ou seja, uma certa arte de compor cartas feitas de referenciais de conhecimento, mas também fabulosos rituais a partir dos quais ele posiciona suas angústias e tenta administrar suas inclusões e pulsações de todo tipo.

De acordo com os entrevistados, algumas dificuldades foram encontradas pelos portadores de transtorno mental dentro das residências, referem-se às próprias limitações que foram a eles impostas pe- los muitos anos institucionalizados, quando necessitavam obedecer e respeitar as regras sem poder de decisão, quando foram abolidos os desejos e despidos de sua própria identidade. Neste momento, a vida se revela com perspectivas de poder assumir novas subjetivações, de exercer sua autonomia e ajustar-se a um novo modelo de vida pós-manicômio.

\section{Resgate da cidadania como emancipação}

A desinstitucionalização implica no resgate da cidadania como processo de valorização dos seres humanos, para que possam ser compreendidos como pessoas, com direitos a tomar decisões, com oportunidades de fazerem-se cidadãos e de terem a sua vontade e fala validadas. As entrevistas também apontam para a superação da pessoa enquanto portadora de transtorno mental, enquanto cidadão sujeito de direitos e desejos.

A cidadania do paciente psiquiátrico não é a simples restituição de seus direitos formais, mas a construção de seus direitos substanciais, e é dentro de tal construção (afetiva, relacional, material, habitacional, produtiva) que se encontra a única reabilitação possível. ${ }^{3}$ [... estão podendo exercer isso agora aos poucos dentro da sua própria casa, não digo tanto ainda na sociedade porque tudo ainda é um primeiro passo [...] o primeiro passo é se redescobrir dentro da sua própria casa, [...] para depois talvez serem redescobertos pela sociedade (A3).

Para reabilitar o paciente institucionalizado que viveu muitos anos "vegetando" nos manicômios, seria importante que os profissionais se esforçassem para que nele fossem despertados sentimentos contrários ao poder que o determinou e o institucionalizou, mesmo antes de construir um espaço acolhedor e humano do qual também ele necessita. ${ }^{10}$ Despertado esse sentimento, o vazio emocional em que o doente vem vivendo há anos voltará a ser tomado pelas forças pessoais de reação e de conflito, ou seja, o único ponto de apoio possível para sua reabilitação: sua agressividade. [...] sair do manicômio não garante a inclusão social, nem a desinterdição judicial garante a conquista da cidadania (A6).

As formulações do campo pós-modernista constituem um dos paradoxos fundamentais no campo das políticas sociais e da cidadania. Tal dilema é ainda maior na saúde mental, pois articula de forma complexa conquistas no campo social e na atenção psicossocial com o desenvolvimento dos processos de subjetivação que buscam a normatização social. Isso fica mais visível na medida em que a reivenção 
da vida nos processos de desinstitucionalização implica em organizar alternativas de sociabilidade, trabalho, moradia, lazer, educação, substitutivos à redução dessas esferas de vida dentro das instituições psiquiátricas convencionais. ${ }^{11}$

As respostas que se obtêm com as intervenções constituem-se em um fio que conduz para as avaliações das ações terapêuticas empregadas. Um ponto decisivo de tensão na condução do tratamento inclui trabalho, lazer e habitação, numa perspectiva que visa ao processo de emancipação do paciente. Reduzir o sujeito à categoria de excluído social é condená-lo a sofrer os efeitos de qualquer determinação que ignora o desejo e a intenção nas ações humanas. Direitos iguais e acesso a uma assistência digna e de qualidade não se confunde em qualquer momento com padronização de atendimento ou com a crença de que o que é bom para um vale para todos. A premissa da desigualdade no que comporta às possibilidades de acolher diferenças e produzir soluções diferenciadas é fundamental. ${ }^{12}$ [...] o cuidadoé respeitando acho essa coisa muito sutil, até que ponto a gente faz. uma interferência que é de nosso desejo sem desrespeitar o desejo desse indivíduo [...] até que ponto tu fala do que é teu ou trata de maneira que tu está depositando, colocando uma coisa que é tua e até que ponto tu está de repente atendendo os desejos dessas pessoas ou apagando, não respeitando esses desejos [...] (A4).

Dos depoimentos dos profissionais, conclui-se que existem refinamentos conceituais que se refletem na prática cotidiana através da reintegração da pessoa ao convívio social, com projetos que visam à assistência digna, que envolvem a participação do indivíduo, a integralidade do cuidado, resgatando as potencialidades [...] de vida do sujeito, possibilitando a produção de vida. [...] e está posta nas potências do indivíduo [...] de estar se assumindo como sujeito, como sujeito de tomar decisões, de estarem podendo fazer sua comida, de estarem podendo ir comprar suas próprias roupas não usar roupas marcadas, identificar que ele é de tal unidade, poder ter o seu espacso, que não é um espaço coletivo, é um espaço de uma casa, é um espaço que ele pode assumir como seu [...] (A4).

A possibilidade de reinventar o cotidiano trazido pela destruição que o capitalismo opera nos modelos de vida tradicionais é, também, condição de possibilidades para o que se poderia chamar de plasticidade sem precedentes do mundo contemporâneo, no que diz respeito às possibilidades de invenção de novos modos de vida. ${ }^{13}$ Essa plasticidade é a contrapartida positiva da desertificação, ou seja, a possibilidade de que do deserto brotem flores e frutos caso saibamos irrigá-los. [...] eles poderem se descobrir enquanto pessoa que, até então, eles eram nada mais que uma multidão dentro de um hospital (A3).

Geralmente, quando as pessoas saem do manicômio, deparam-se com a violência da assistência social, que costuma partir de um processo de invalidação, de negação das possibilidades das pessoas, que não parece correto, mas é o que comumente ocorre. Existem possibilidades mesmo que residuais, de dar, de trocar, de ser, de produzir. Mas o juízo da improdutividade que está na base de ser assistido é um direito que nega as pessoas, que as invalida, que destrói as residualidades, as potencialidades das pessoas e as remete ao improdutivo.?

As residências terapêuticas são uma alternativa de cuidado que trabalha como um recurso projetado para ajudar no desenvolvimento das potencialidades dos ex-pacientes em um ambiente democrático e terapêutico onde haja respeito e uma realização dos direitos humanos, do respeito à vida, da liberdade e da segurança. Todos têm o direito de recomeçar como pessoa, de ter propriedade, sozinhos ou na associação com outra pessoa, têm direito à liberdade de opinião e de expressão, a descansar, ao lazer e a fazer uso apropriado do tempo. ${ }^{14}$

\section{Processo educativo como cuidado: resgatar habilidades e autonomia}

Esta área temática aborda a prática educativa que permite o desenvolvimento de habilidades, potencialidades e possibilidades dos moradores, construindo assim um cuidado individualizado, qualificado e humanizado, que permite a inclusão de dignidade e produção de vida. Também é discutido o processo referente ao resgate das habilidades da vida cotidiana e a autonomia das pessoas com transtorno mental de longa evolução.

Este estudo revela que é necessária uma prática reabilitadora voltada para a educação, uma reaprendizagem das atividades diárias da vida; é necessário motivar essas pessoas para que elas desenvolvam estes ensinamentos sozinhas, não discriminando, nem excluindo, mas sim, respeitando o tempo de cada pessoa no processo. [...] a gente tinha uma expectativa maior e não conseguiram alcançar os objetivos que nós imaginávamos, para eles, desde o levantar de manhã e escolher a própria roupa, o lidar com o dinheiro, o lidar com a seu própria medicação, ou seja, muitos itens que a equipe toda tem que acompanhar em muitos momentos (A3).

A educação é de fundamental importância para se atingir a cidadania do doente mental. As 
práticas de reinserção e reabilitação perpassam pela educação, assim como a construção e reconstrução dos sujeitos. Dentro desta perspectiva, o planejamento educacional participativo poderá ser apontado como uma das estratégias possíveis, inseridas nas propostas da reabilitação psicossocial. As palavraschave desta construção educacional, saber/popular, educação participativa, planejamento participativo, envolvimento e autonomia rementem às práticas $\mathrm{da}$ reabilitação e reinserção social, enquadrando-se como o melhor meio de emancipação do ser humano.

Neste contexto, percebe-se que as habilidades e aptidões precisam de um constante aprendizado, um reforçar aquelas questões de vida diária mais elementares que foram esquecidas atrás dos muros, visando assim estimular a auto-estima, o cuidado com a higiene, o atendimento das atividades diárias, minimizando as limitações, potencializando os hábitos saudáveis e viabilizando sua autonomia para a vida na comunidade. [...] redescobrindo como trabalhar [...] pela experiência do acontecer ou seja, os moradores vieram para as casas a gente primeiramente deixou que as coisas fluissem, achávamos que tudo iria acontecer ao natural seria tudo muito fácil e não foi, a gente percebeu que em muitos momentos a gente tem que estar junto talvez até um pouco norteando o que eles devem fazer (A3).

$\mathrm{O}$ entendimento desses fatos confirma que a adaptação às mudanças de um modelo institucional para um residencial requer um aprender ou reaprender as questões básicas da vida diária, uma superação do que foi um dia podado e trancafiado nos espaços intramuros. Entretanto, estas possibilidades de aprendizagem trazem em seu bojo um novo sentido de como superar o processo da doença e da reinserção social, resgatando o espaço privilegiado de formação de sujeitos produtores de mudanças, redimensionando o seu potencial transformador. $A$ possibilidade das pessoas de ressignificar suas próprias vidas no espaço social da cidade, nas suas casas: dormindo, acordando, comendo, saindo, sem precisar autorização para faz̧er qualquer coisa que queiram [...] uma rede substitutiva que possibilite intervençôes singulares de acordo com as potencialidades e dificuldades de cada sujeito (A6).

A autonomia é determinada pela capacidade de elaborar projetos, isto é, ações práticas que modifiquem as ações concretas de vida. ${ }^{15} \mathrm{O}$ autor contextualiza a autonomia como a capacidade de uma pessoa gerar normas e ordens para a sua vida, conforme as diversas situações que enfrente. Coloca que ser mais autônomo quanto mais dependente de tantas coisas, pode ser, pois implica nas possibilidades de estabelecer novas normas, novos ordenamen- tos para a vida. Não se trata de confundir autonomia com independência, pois dependentes somos todos, pois a questão dos usuários é uma questão excessivamente dependente de poucas relações. E essa relação restrita é que diminui a sua autonomia. [...] o resgate de algumas habilidades que por questões institucionais os pacientes praticamente esqueceram [...] enquanto que, quando a gente está na casa da gente a gente que tem que fazer isso, resgatar essas habilidades on atividades de vida diária [...] dá uma certa condição de autonomia [...] sente mais seguro, fico mais autônomo, eu acho que isso é fundamental para diferenciar essas atividades dos residenciais terapêuticos, o resgate da autonomia que se chama de cidadania (A5).

Os profissionais que cuidam de moradores dos serviços residenciais terapêuticos deverão saber dosar sempre o quanto de cuidado deverá ser oferecido para auxiliar na aquisição de autonomia pelo usuário, numa negociação constante. Este novo lugar de trabalho também vai requerer dos profissionais a realização de atividades que vão muito além de sua formação inicial, tais como: auxiliar em tarefas domésticas, ajudar no pagamento de contas, na administração do próprio dinheiro, entre outros, requerendo dos trabalhadores o desenvolvimento de novas formas de cuidar. ${ }^{2}$

De acordo com os entrevistados, é preciso desenvolver um processo educativo por parte dos profissionais, permitindo resgatar as habilidades e potencialidades dos indivíduos nas questões de vida diária, ou reforçar aquelas habilidades que, por questões institucionais, foram esquecidas, viabilizando a sua autonomia, esta entendida como a capacidade de adquirir novos ordenamentos para sua vida cotidiana.

\section{Operacionalização das moradias}

Esta área da pesquisa descreve a operacionalização da modalidade assistencial substitutiva, as residências terapêuticas, que permitem redirecionar recursos e atenção para as ações no serviço, estimulando a inserção social e a prestação de cuidados aos portadores de transtorno mental. Para além das disposições legais que regem as residências terapêuticas, existem, no cotidiano dos serviços, atividades que contemplam o acesso à habitação, educação, trabalho, cultura e lazer.

Estes dispositivos demandam cuidados personalizados, envolvendo uma abordagem compreendida como intervenção no universo de relações interpessoais do paciente (família, escola, vizinhança e trabalho). ${ }^{8}$ A casa se apresenta como 
um local de territorialidade, compreendida como um lugar de pertença. Também existe a possibilidade de criação de um lugar de acolhimento que pressupõe uma ambiência afetiva. ${ }^{8}$

O que foi exposto por diversos autores, corrobora a idéia da necessidade de um serviço residencial para os portadores de transtorno mental, para que eles conquistem um espaço de territorialidade, ou seja, a casa do paciente, que possam ter uma reapropriação do espaço que é seu, uma recuperação das relações interpessoais, o viver em família, com os vizinhos, com a escola e alguns com o próprio trabalho. [...] os cuidados, em tudo o que demanda conservação, muitas coisas têm que ser assumidas pelos próprios moradores, [...] no futuro eles deverão assumir essa parte, a casa já foi toda ela mobiliada com as coisas básicas [...] Em função de a gente morar em uma vila então teve benfeitorias que foram feitas pelos próprios moradores [...] dependendo do que é o próprio hospital conserta, ou a gente compra o que tem que ser e vem o pessoal da manutenção e faz a colocação, instalação (A1).

Nos discursos, evidencia-se que uma residência terapêutica exige uma reestruturação do espaço, uma adequação dos moradores a este novo modelo de atenção. Os moradores contam com assistência em saúde mental e com toda a infra-estrutura necessária. Algumas responsabilidades são assumidas pelos próprios moradores, outras são vinculadas ao hospital, como: conservação, instalação e manutenção. A alimentação tanto pode ser adquirida do hospital como realizada pelos próprios moradores. Estes têm a possibilidade de receber um auxílio para a reabilitação psicossocial, benefício do "Programa de Volta para Casa”, para que possam reconstruir suas vidas. Os moradores também participam de cooperativas e de atividades como reciclagem ou na reabilitação. Algumas atividades são desenvolvidas juntamente com o pessoal do bairro onde moram. São realizadas reuniões da equipe e com os moradores, o objetivo destas consiste nas trocas de informações entre os moradores, bem como permitem trabalhar questões de convivência na moradia, em razão de ser um espaço coletivo de sustentação das instabilidades emocionais e dificuldades que surgem no cotidiano. [...] ainda é vinculado ao hospital, em termos de conserto de limpeza, algumas vezes, mas dentro do possivel os moradores tem que dar conta dessas coisas, tanto de fazer comida apesar deles receberem comida do hospital ainda in natura eles recebem os produtos e cozinham. Muitas vezes alguns buscam comida pronta, mas a maioria tem cozinhado (A4).

Deve-se considerar eventuais inseguranças em deixar o hospital, via de regra, uma referência segura para as pessoas institucionalizadas. Há que se montar estratégias que permitam aos futuros moradores estabelecer vínculos de confiança com os profissionais e com a proposta. Há muito o que ser resgatado: histórias, vínculos afetivos e projetos. É essencial a existência de um ou mais profissionais de referência para cada morador e o estabelecimento de um projeto terapêutico individual. Um longo processo de reabilitação psicossocial tem início com a ida para o serviço residencial terapêutico. ${ }^{2}$ Os moradores, eles recebem, alguns têm beneficios, porque precisam de dinheiro para se manter lá, é complicado isso, é difícil a gente simplesmente mudar uma pessoa para morar numa casa com uma idéia de que está convivendo com a sociedade se a pessoa não tem dinheiro para comer e não fazer nada, como é que a pessoa vai viver numa idéia de está convivendo na sua casa, então alguns benefícios, aposentadoria, alguns têm dinheiro de salário, de trabalho (A4).

As residências devem ser articuladas a uma rede de apoio que proporciona aos moradores melhores condições de adaptação, mantendo-se os laços afetivos com os profissionais, proporcionando um ambiente de acolhimento, onde as necessidades dos usuários sejam preponderantes à organização do serviço, isto é, o serviço deve se adaptar às especificidades dos usuários e não o contrário.

As entrevistas revelam que permanece um vínculo entre o hospital psiquiátrico e os moradores das residências, pelas próprias questões de conservação, instalação, manutenção mantidas pela instituição. Leva-se em conta que algumas responsabilidades são assumidas pelos próprios moradores das residências, o que é desejável, outras especificidades/demandas são trabalhadas com o grupo, como questões relativas às dificuldades de relacionamento, autonomia e responsabilidades quanto aos cuidados pessoais, culinária, cuidados com a moradia, relação com vizinhos, dentre outros.

\section{CONSIDERAÇÕES FINAIS}

Os resultados desta pesquisa fazem refletir a respeito das conquistas no campo da reforma psiquiátrica, através do surgimento das residências terapêuticas, como um modelo de reabilitação psicossocial aos indivíduos institucionalizados de longa evolução. O habitar, a noção de lar, remetem a estabelecer laços, criar espaços de circulação, estabelecer contratos materiais e afetivos, estimular a autonomia possível, respeitar as pessoas na sua individualidade e singularidade, estimular a reintegração com a comunidade e criar oportunidades para estes 
sujeitos nos diversos contextos do cotidiano, promovendo produção de vida além dos muros reais ou simbólicos, permitindo a reconstrução pessoal, social e principalmente a conquista da cidadania.

Ao falar da inserção dos portadores de transtornos mentais crônicos, deve-se não apenas levar em consideração a sociedade que os exclui, mas a sua própria subjetividade, as limitações decorrentes de muitos anos de institucionalização, como a mortificação do eu, a perda da identidade, a abolição do desejo, a perda da subjetividade através da objetividade institucional. Esta outra via está voltada para as reais necessidades dos portadores de sofrimento psíquico, buscando romper com a cronificação e a travessia para os espaços da reabilitação e construção/reconstrução da autonomia para a vida cotidiana.

Cabe ressaltar que é preciso construir um referencial teórico embasado nas práticas que se efetivam nas residências terapêuticas, permitindo reflexões, construindo conceitos que darão margem a outros estudos que possam gerar subsídios para os trabalhadores de saúde mental e assim consolidar avanços nos novos dispositivos em saúde mental no contexto da reforma psiquiátrica.

\section{REFERÊNCIAS}

1 Dias MTG, Cruz RAC, Frichembruder SC, Monteiro JR. Projeto Morada São Pedro. In: Ferla A, Fagundes SMS, organizadores. O fazer em saúde coletiva: inovações da atenção à saúde no Rio Grande do Sul. Porto Alegre (RS): Dacasa; 2002.

2 Ministério da Saúde (BR), Secretaria de Atenção à Saúde, Departamento de Ações Programáticas Estratégicas. Residências terapêuticas: o que são, para que servem? Brasília (DF): Ministério da Saúde; 2004.

3 Saraceno B. Libertando identidades: da reabilitação psicossocial à cidadania possível. 2a ed. Rio de Janeiro (RJ): Instituto Franco Basaglia/Te Corá; 2001.

4 Minayo MCS. O desafio do conhecimento: pesquisa qualitativa em enfermagem. 7a ed. São Paulo (SP)/Rio de Janeiro (RJ): Hucitec/Abrasco; 2000.
5 Ministério da Saúde (BR), Conselho Nacional de Saúde, Comitê Nacional de Ética em Pesquisa em Seres Humanos. Resolução No 196 de 10 de outubro de 1996: diretrizes e normas regulamentadoras de pesquisa envolvendo seres humanos. Brasília (DF): O Conselho; 1996.

6 Pereira VP, Borenstein MS. Iluminando as vivências de mulheres portadoras de transtornos psíquicos e moradoras de uma residência terapêutica. Texto Contexto Enferm. 2004 Out-Dez; 13 (4): 527-34.

7 Rotelli F. O inventário das subtrações. In: Rotelli F, De Leonardis O, Mauri D. Desinstitucionalização. 2a ed. São Paulo (SP): Hucitec; 2001.

8 Guljor APF. Os centros de atenção psicossocial: um estudo sobre a transformação do modelo assistencial em saúde mental [dissertação]. Rio de Janeiro (RJ): Fundação Oswaldo Cruz/Escola Nacional de Saúde Pública; 2003.

9 Guattari F. Linguagem, consciência e sociedade. In: Lancetti A. Saúdeloucura 2. 3a ed. São Paulo (SP): Hucitec; 2000.

10 Basaglia F. A instituição negada: relato de um hospital psiquiátrico. 2a ed. Rio de Janeiro (RJ): Graal; 1991.

11 Vasconcelos EM. Reinvenção da cidadania, empowerment no campo da saúde mental e estratégia política no movimento dos usuários. In: Amarante P. Ensaios, subjetividade, saúde mental e sociedade. Rio de Janeiro (RJ): Fiocruz; 2000.

12 Macedo ALP, Maron MGR. A clínica e a reforma psiquiátrica: um novo paradigma? Jor. Bras. Psiquiatria. 1997 Abr; 4 (46): 205-11.

13 Rauter C. Oficinas para quê?: uma proposta éticoestético-política para oficinas terapêuticas. In: Amarante P. Ensaios, subjetividade, saúde mental e sociedade. Rio de Janeiro (RJ): Fiocruz; 2000.

14 Vietta EP, Saeki T, Rosa DOS, Ferreira, LA. Halfway house: an alternative to rescue the rights and citizenship of the mentally ill person. International Jour. Psychosocial Rehabilitation.2000; 5: 19-28 [acesso em 2005 Abr 03]. Disponível em: http://www. psychosocial.com

15 Kinoshita RT. Contratualidade e reabilitação psicossocial. In: Pitta A. Reabilitação psicossocial no Brasil. 2a ed. São Paulo (SP): Hucitec; 2001. 